\title{
Striving for an Optimal Entry into the Chemical \& Pharmaceutical Job Market
}

Romain Dubey ${ }^{\star a b c}$, Andreas Gimpel ${ }^{a}$, Konstantin Zouboulis ${ }^{\mathrm{a}}$, and Markus Böckerac

${ }^{*}$ Correspondence: R. Dubey, E-mail: romain.dubey@chemtogether.ethz.ch aDepartment of Chemistry and Applied Biosciences, ETH Zurich, $\mathrm{CH}-8093$ Zurich, ${ }^{\mathrm{b}}$ Empa, Swiss Federal Laboratories for Materials Science \& Technology, $\mathrm{CH}-8600$ Dübendorf, ${ }^{\circ}$ Chemtogether, VCS, Postfach 84, Wolfgang-Pauli-Str. 9 , $\mathrm{CH}-8093$ Zürich

\section{Keywords: Chemical sciences · Graduate jobs · Job market}

We are a group of Master and $\mathrm{PhD}$ students, currently or formerly active in student associations, and responsible for industry relations. In this context and in cooperation with the Swiss Chemical Society, we conducted a survey involving 86 students in chemistry, chemical engineering, and interdisciplinary sciences (BSc, MSc, and PhD) within the Department for Chemistry and Applied Biosciences (D-CHAB) at ETH Zurich. The aim of this study was to understand the students' expectations toward the job market and to compare them to reality. Based on the results and our own experiences, we then propose a number of measures to ease the transition from the academic world to the private sector.

The chemical and pharmaceutical industries are of central importance to the Swiss economy. In 2019, these industries employed more than 74'000 people, published more than $38 \%$ of the top Swiss patents, and their products made up for $47 \%$ of total exports in Switzerland. ${ }^{[1]}$ High quality training of young chemists is therefore vital for the long-term success of the Swiss economy. It is thus also of great importance to ensure that entry into the job market for young and highly qualified chemists \& chemical engineers is as smooth and as successful as possible.

To identify the situation students find themselves in with respect to the job market, the 86 respondents were surveyed as to their current job prospects and the status of their job search. It was found that $49 \%$ of the participants expect to find a job in industrial R\&D, while only $14 \%$ aim at an academic career (Fig. 1). Furthermore, the average chemistry student at the Master level is not actively looking for a job, while most chemical engineers are either already applying or actively looking for positions. In parallel, the more the chemistry students progress with their studies, the more likely they are to think their job search will prove difficult. Furthermore, a majority of students, about $58 \%$ of chemists and $90 \%$ of chemical engineers, are interested in doing an internship.

There is a scarcity of (assistant) professor and core R\&D industrial positions in Europe. For example, in Germany, only 6\% of science, technology, engineering and mathematics (STEM) $\mathrm{PhD}$ holders obtain a full-time position in academia. ${ }^{[2]}$ The ratio of students aiming at a career in academia in our study is closer to reality than the respondents to Nature's $2019 \mathrm{PhD}$ survey, in which $56 \%$ said that academia is their first choice for a career. ${ }^{[3]}$ Nevertheless, the expectations of the students are too strongly biased towards R\&D; they underestimate several other important branches, such as consulting, intellectual property, and governmental institutions. Regardless of the direction and education level, we generally identify a lack of awareness about the plethora of different career paths and types of positions available on the job market. Indeed, there are various positions outside of academia and core industrial R\&D, such as market research, procurement or logistics, just to name a few. Along these lines,
Where students aim to work
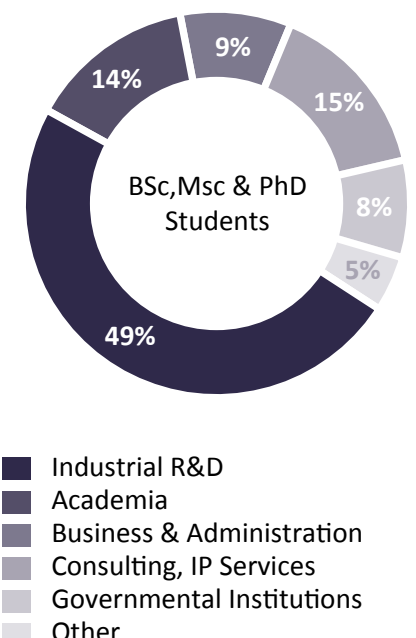

Fig. 1. Where chemistry, chemical engineering and interdisciplinary science students aim to work.

the students' interest in internships highlights their desire to learn about other private-sector career paths and gain insight into the industrial world.

In light of these findings, we focused most closely on internships, namely on understanding the expectations of the students, on the optimal moment for this kind of work experience, and the actual experiences made by students during their internships. Notably, $88 \%$ of the students expect an internship to help them gain insight into the profession, while only $26 \%$ are seeking to secure a permanent position through an internship (Fig. 2a). When asked about their experiences during their internship, two thirds of the surveyed students reported that it helped them build a professional network. A large majority found their existing qualifications to be sufficient for their traineeship, and as many as $92 \%$ of the students had a positive experience during their internship in general. Based on these observations, we conclude that internships are an excellent opportunity for students to explore a profession before committing to a field. Moreover, internships are an excellent branding tool for companies with a long-term recruitment and talent acquisition strategy; nearly half of the students reported that they are interested in returning to the company at a later time if they were offered a position.

Our results also show that Master students are markedly more interested in internships than undergraduate or $\mathrm{PhD}$ students, but the interest of the latter is nevertheless not negligible. Thought of as a tool to gain insight into a profession, internships and the level of responsibilities they entail are in our opinion not ideally tailored to $\mathrm{PhD}$ students whose training as future project leaders should make them eligible for standard entry-level positions. Whether the interest in an internship expressed by $\mathrm{PhD}$ students is caused by an uncertainty in their career decisions and/or a lack of entry-level positions available without prior work experience is subject to speculation.

We therefore assess the best timeframe for an internship to be immediately after graduation with a Bachelor degree, during 
a Students' expectations from an internship

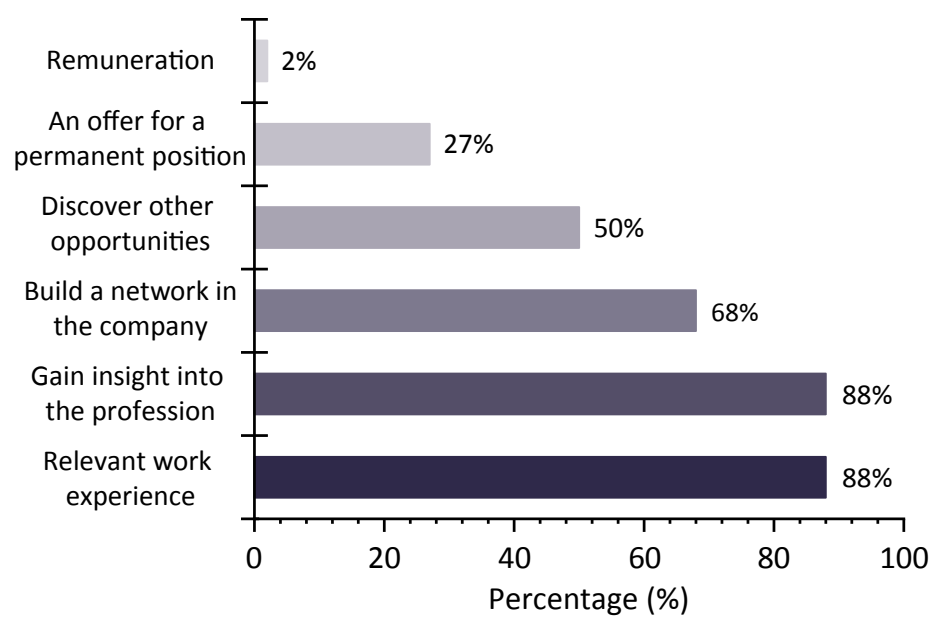

b Students' support for intensifying industry contacts

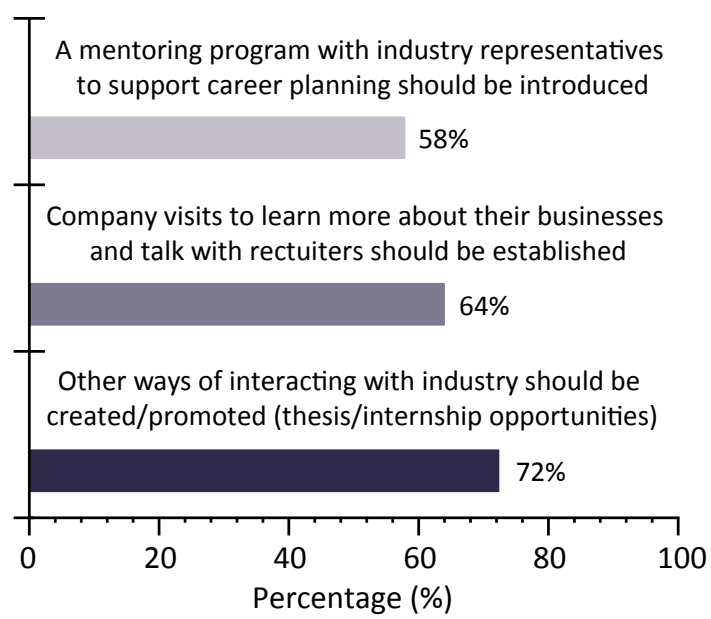

Fig. 2. (a) Students' expectations from an internship. (b) Students' opinions on how to improve the contact between academia and industry.

the Master program as part of the curriculum (e.g. as a research project or Master thesis) or prior to the start of $\mathrm{PhD}$ studies. However, the search for internships is laborious; there is a mismatch between the requirements set by the students' academic curriculum and the type of internships typically offered in industry, especially for research projects as a part of the Master degree studies. According to our experience, many companies will not accept students in part-time positions, and a majority consider students to be productive only after a formation period of a few months, i.e. comparable to the duration of one semester. Whereas many of the larger companies offer well established internship programs, smaller companies often do not consider offering internships, possibly because they lack resources and the experience in hosting interns. At the same time, the arrangement of the STEM curricula in terms of agenda at many universities renders it challenging for students to consider doing internships and Master theses in industry, e.g. in cases where exams are set late in a lecture-free period or when the time imparted for Master theses is relatively short.

We recommend that both parties, academia and industry, should adopt more flexibility. Firstly, we encourage the industry to create more internships positions and to re-evaluate the advantages brought by hiring interns. In particular, we wish to point out that more than $70 \%$ of our respondents felt that they had the skills to tackle the tasks they were given during their internship; this suggests that most interns are able to be productive within a short time span. Moreover, we highlight again that half of the students would seriously consider permanent employment with the company in which they had interned. In our experience, there is an information gap between companies, especially smaller companies, and students, in terms of communicating requirements for internships or other opportunities in industry. Many companies wishing to reach students to advertise opportunities do not know where to start. To remedy this information gap and gain insight into possible approaches to building bridges, we asked students for their opinion on an intensification of the relations between academia and industry. Around $70 \%$ of chemical engineering students greatly value the option to do a Master thesis in industry. Approximately the same number of respondents wish that other ways of interacting with industry would be created or promoted, through the creation of more thesis/research projects and internship opportunities (Fig. 2b).

In addition to internships and research projects, we would like to suggest other means to bridge the above-mentioned gaps. Two thirds of the students surveyed feel that excursions (company visits) are very useful to learn about a business and to talk with potential employers. These events can easily be organized in coop- eration with student organizations, the university departments, or if available, the university career centers. Interestingly, a majority of students would support an optional mentoring program involving industry representatives and/or alumni members to support career planning. We also recommend an intensification of industry participation in career fairs such as 'Chemtogether' ( $w w w$. chemtogether.ethz.ch), 'Life Science Day' (www.lifescienceyoungscientists.uzh.ch/en/events/ZurichLifeScienceDay), and 'Polymesse' (www.polymesse.ch), at which students can interact with company representatives in person (Note that $80 \%$ of the students looking for more contact with industry and/or their first job actually visited a career fair). Still, at a career fair, a majority of students is not yet looking for permanent positions, but rather for opportunities to gain insights into professions and to learn about the expectations of prospective employers. In general, students benefit most from discussions with representatives with a scientific background, ideally persons who started their career not too long ago, i.e. still being familiar with the student sensitivities at that stage. Alternative approaches are sponsored lectures, $\mathrm{MSc}$ or PhD scholarships. The chemistry student association at ETH Zurich (VCS) and its industrial partners have also had good experiences with student-directed sponsorships such as for books or laboratory equipment. Personal networking-focused career events would also offer enormous visibility for companies at low costs. For example, the so-called 'Career \& Beer' event either organized by the ETH Career Center or directly by the Union of the Assistants at the Chemical Labs of ETH Zurich (VAC), during which an informal aperitif followed by the company's presentation, facilitates opportunities to exchange experiences between students and representatives who managed the transition into industry successfully.

In conclusion, we strive for a future in which the relations between industry and academia will be intensified. Our goal is that every qualified and motivated student shall be able to gain insight into the professional world early on in her or his education. In our opinion, as echoed by many other student organizations, more unbiased and realistic information about the existing opportunities and industry expectations would help students to improve their readiness level to obtain a permanent entry-level position soon after their graduation.

Received: August 7, 2020

[1] scienceindustries annual report 2019, https://www.scienceindustries.ch/ services/360/jahresberichte, accessed 18.07.2020.

[2] D. Cyranoski, N. Gilbert, H. Ledford, A. Nayar, M. Yahia, Nature 2011, 472, 276.

[3] C. Woolston, Nature, 2019, 575, 403. 